\title{
Neuraxial anesthesia improves long-term survival after total joint replacement: a retrospective nationwide population-based study in Taiwan
}

\section{L'anesthésie neuraxiale améliore la survie à long terme après arthroplastie totale: étude rétrospective de population à l'échelle nationale à Taiwan}

\author{
Wei-Hung Chen, MD • Kuo-Chuan Hung, MD • \\ Ping-Heng Tan, MD, PhD $\cdot$ Hon-Yi Shi, DrPH \\ Received: 15 April 2014/ Accepted: 13 January 2015/Published online: 22 January 2015 \\ (C) Canadian Anesthesiologists' Society 2015
}

\begin{abstract}
Introduction This study explored the effects of general (GA) and neuraxial (NA) anesthesia on the outcomes of primary total joint replacement (TJR) in terms of postoperative mortality, length of stay (LOS), and hospital treatment costs.

Methods From 1997 to 2010, this nationwide population-based study retrospectively evaluated 7,977 patients in Taiwan who underwent primary total hip or knee replacement. We generated two propensity-scorematched subgroups, each containing an equal number of patients who underwent TJR with either GA or NA.

Results Of the 7,977 patients, 2,990 (37.5\%) underwent GA and 4,987 (62.5\%) underwent NA. Propensity-score

Author contributions Wei-Hung Chen and Hon-Yi Shi performed the literature search and contributed to the study design. They performed all the data collection and wrote the first version of the manuscript. Kuo-Chuan Hung and Ping-Heng Tan were involved in the literature search and designed the study. They were also involved in data analysis and data interpretation and made several revisions to the manuscript. All authors provided intellectual contributions to this work.
\end{abstract}

W.-H. Chen, MD - K.-C. Hung, MD - P.-H. Tan, MD, PhD Department of Anesthesiology, E-DA Hospital, I-Shou University, Kaohsiung, Taiwan

W.-H. Chen, MD · H.-Y. Shi, DrPH ( $\square)$

Department of Healthcare Administration and Medical Informatics, Kaohsiung Medical University, 100-Shih-Chun 1st Road, Kaohsiung 80708, Taiwan

e-mail: hshi@kmu.edu.tw

P.-H. Tan, MD, PhD

Department of Biomedical Engineering, E-DA Hospital, I-Shou University, Kaohsiung, Taiwan matching was used to create comparable GA and NA groups adjusted for age, sex, comorbidities, surgery type, hospital volume, and surgeon volume. Survival over the first three years following surgery was similar. The proportion of patients alive up to 14 years postoperatively for those undergoing NA was $58.2 \%$ (95\% confidence interval [CI] 50.4 to 66.0), and for those undergoing GA it was $57.3 \%$ (95\% CI 51.4 to 63.2). Neuraxial anesthesia was associated with lower median [interquartile range; IQR] hospital treatment cost $(\$ 4,079$ [3,805-4,444] vs \$4,113 [3,812-4,568]; $P<0.001)$ and shorter median [IQR] LOS (8 [7-10] days vs 8 [6-10] days, respectively; $P=0.024$ ).

Conclusions Our results support the use of NA for primary TJR. The improvements in hospital costs persist even when anesthesia costs are removed. The mechanism underlying the association between NA and long-term survival is unknown.

\footnotetext{
Résumé

Introduction Cette étude a exploré les effets de l'anesthésie générale $(A G)$ et de l'anesthésie neuraxiale (AN) sur les aboutissements de l'arthroplastie totale de première intention (AT) en termes de mortalité postopératoire, de durée de séjour (DS) et de coûts de traitements hospitaliers.

Méthodes Cette étude basée sur la population nationale de Taiwan a évalué, rétrospectivement de 1997 à 2010, 7977 patients qui avaient subi une arthroplastie totale de première intention de hanche ou de genou. Nous avons créé deux sous-groupes appariés par score de propension, chacun incluant un nombre égal de patients ayant subi une AT sous $A G$ ou $A N$.
} 
Résultats Sur les 7977 patients, 2990 (37,5\%) ont bénéficié d'une $A G$ et 4987 (62,5\%) ont bénéficié d'une $A N$. L'appariement du score de propension a servi à créer des groupes $A G$ et AN comparables, ajustés pour l'âge, le sexe, les comorbidités, le type de chirurgie, le volume d'activité de l'hôpital et le volume d'activité du chirurgien. La survie au cours des trois premières années suivant la chirurgie a été semblable. Les pourcentages de patients vivants jusqu'à 14 ans après l'opération ont été, respectivement, pour les patients ayant subi une AN $58,2 \%$ (intervalle de confiance [IC] à 95\%: 50,4 à 66,0) et ceux ayant subi une AG 57,3 \% (IC à $95 \%: 51,4$ à 63,2). L'anesthésie neuraxiale a été associée à un coût de traitement hospitalier médian (intervalle interquartile; IQR) plus bas (4 $079 \$[3$ 805-4 444] contre $4113 \$$ [3 812-4 568]; $P<0,001)$ et une DS médiane [IQR] plus courte (8 [7-10] jours contre 8 [6-10] jours; $P=0,024$ ). Conclusions Nos résultats sont en faveur de l'utilisation de l'AN pour les AT de première intention. Les améliorations observées dans les coûts hospitaliers persistent même lorsque les coûts de l'anesthésie sont soustraits du calcul. Le mécanisme sous-tendant l'association entre AN et survie à long terme est inconnu.

The demand for primary total joint replacement (TJR) in developed countries has been growing rapidly. It is expected to surpass the 4 million mark in the United States by 2030 (3.48 million total knee replacements and 0.57 million total hip replacements). ${ }^{1}$ With the expected increase in TJR procedures, it is important to investigate parameters that could optimize medical outcomes as well as resource allocation and utilization. The use of neuraxial anesthesia (NA), which includes both spinal anesthesia and epidural anesthesia, may reduce hypercoagulability following surgery, increase regional blood flow, reduce the stress response, and provide good pain control., ${ }^{2,3}$ Previous studies reported that orthopedic procedures under NA may be associated with a lower 30-day overall complication rate, better 30-day survival, a shorter hospital stay, and fewer blood transfusions than general anesthesia (GA). ${ }^{4-8}$ Considering the short-term benefit, NA may be preferable for patients undergoing TJR. Little is known about the effect of anesthetic management on longterm outcomes.

In recent years, some studies reported an association between anesthetic management and cancer recurrence. ${ }^{9,10}$ These findings may therefore imply an association between anesthetic management and long-term outcome. Although NA may reduce the number of postoperative complications and improve short-term mortality in patients undergoing
TJR, it remains unknown whether it may also influence long-term survival in these patients. ${ }^{11,12}$

The primary aim of this study was to evaluate the effect of anesthetic management on long-term survival rate for patients undergoing TJR. The short-term survival rate, length of stay (LOS), and hospital treatment costs were also evaluated. We hypothesized that NA may improve the long-term overall survival rate when compared with GA in TJR patients.

\section{Methods}

Database and study design

The institutional review board (IRB) of Kaohsiung Medical University Hospital issued a formal written waiver of the need for consent (KMUH-IRB-EXEMPT-20140055, October 2014). Data for the Longitudinal Health Insurance Database (LHID) were collected by systematically and randomly sampling the National Health Insurance Research Database (NHIRD), which includes data for one million individuals. The National Health Research Institute of Taiwan reports that the patients in the LHID and those in the original NHIRD do not significantly differ in sex distribution, age distribution, or average insured payroll-related amount. Data in the NHIRD are de-identified and aggregated for analysis. Written consent of the patients analyzed in this study was not required. The NHIRD provided an opportunity to study the effects of different types of anesthesia on the short- and long-term outcomes of patients who underwent total hip or knee replacement procedures.

The principal procedure codes 81.51 and 81.54 were used to identify total hip and knee replacements, respectively. For patients who had undergone repeated total hip or knee replacement during the study period, we selected only the first procedure as the index hospitalization. We excluded patients for whom the type of anesthesia was not known. Santaguida et al. found that age, sex, comorbidities, and surgical volumes were statistically associated with outcomes after TJR. ${ }^{13}$ The International Classification of Diseases9th revision-Clinical Modification codes (including primary and secondary diagnoses) were used to identify comorbidities for the day prior to the TJR. The primary study outcome was all-cause mortality during the 14-year follow-up. The patient's date of death was determined according to the National Register of Deaths of the National Health Insurance Administration (NHI). The analysis period began from the index date and ended at the death of the patient, withdrawal from NHI, or the end of 2010, whichever occurred first. This is a nationwide population-based study. A formal sample size estimate was not performed. 


\section{Potential confounders}

Clinical significance guided the initial choice of covariates: age, sex, comorbidities, surgery type, and the hospital's characteristics (high or low volume of procedures). The comorbidities included in the model were coronary artery disease, congestive heart failure, cerebrovascular disease, dementia, diabetes, pulmonary disease, renal disease, liver disease, peptic ulcer disease, rheumatological disease, hemiplegia or paraplegia, malignancy, and acquired immune deficiency syndrome. Annual hospital and surgeon volume for TJR were categorized into a dichotomous variable. We chose cutoff points to divide the study population into approximately quarters for each of the years under study (1997 through 2010). ${ }^{14-16}$ Hospitals/surgeons that fell in the highest quartile for the numbers of TJRs performed were considered "high-volume" hospitals/surgeons, and the others were "low-volume" hospitals/surgeons.

\section{Statistical analysis}

To reduce the confounding factors, we conducted a propensityscore-matching model as described by Rosenbaum and Rubin. $^{17}$ Stratification by propensity score replaces covariates that may be present in an observational study with variables for these factors. A non-parsimonious logistic regression model was performed to estimate a propensity score for type of anesthesia. ${ }^{18} \mathrm{We}$ used a structured iterative method to refine this logistic regression model to achieve balance of confounders within the matched pairs. ${ }^{16}$ Confounder balance was measured by the standardised difference. An absolute standardised difference above $10 \%$ represented meaningful imbalance. ${ }^{19}$ We used the approximate nearest neighbour 1:1 without replacement approach by modifying a published macro. ${ }^{17-19}$ The matching macro started to select pairs with an identical propensity score on the tenth decimal and decreased step by step until the first decimal. An additional criterion was being insured for the whole matching calendar year.

Regarding hospital treatment costs, we adjusted hospital treatment costs for different hospital levels based on differences in Bureau of National Health Insurance (BNHI) reimbursements. For each cost center, the cost-to-charge ratio was used to convert charge data into cost data at the hospital level. The total costs included radiology, physical therapy, hospital room, anesthetist, pharmacy, laboratory, special materials, surgeon(s), and others. To reflect changes in real dollar value, cost data were adjusted by the consumer price index for each year under study. Hospital treatment costs were then converted from Taiwan dollars to US dollars at an exchange rate of $30.5: 1$, which was the average rate during 1997-2010.
Continuous variables are expressed as means with standard deviation (SD) or as medians with the interquartile range (IQR). Categorical variables are presented as the frequency and percentage. Shapiro-Wilk test was used to assess for normal distribution. Normally distributed data were analysed by the paired $t$ test. The Wilcoxon rank sum test was used to analyse non-normally distributed data. Differences in categorical variables were assessed using McNemar's test. Overall survival was estimated using the Kaplan-Meier method, and differences were compared using the log-rank test.

Statistical analyses were performed with SPSS version 20.0 (SPSS Inc., Chicago, IL, USA) and SAS Version 9.1 (SAS Institute, Carey, NC, USA). All tests were two-sided. $P<0.05$ was considered statistically significant.

\section{Results}

From the database, we identified 7,977 patients who had undergone a primary total hip $(n=2,318)$ or knee $(n=5,659)$ replacement between January 1, 1997 and December 31, 2010. Of the 7,977 patients, 4,987 were given NA, and the other 2,990 were given GA (Fig. 1). This approach generated two propensity-score-matched subgroups, each containing an equal number of patients who underwent TJR with either GA or NA (2,847 patients in each group) (Fig. 1).

As shown in Table 1, there were significant differences in age, comorbidities, hospital volume, surgeon volume, and surgery type between the two groups before propensityscore matching. Using propensity-score matching, 5,694 patients were equally allocated to two matched anesthesia groups (Table 1). The matched groups were similar with regard to patient age, sex, comorbidities, surgeon volume, surgery type, and hospital volume. The short-term mortality rates for the two groups were similar after propensity-score matching $(0.1 \%$ for both groups at postoperative month 1 and $0.4 \%$ vs $0.6 \%$, respectively, at postoperative month 3 ). As the follow-up continued, NA was found to be associated with a better survival than was shown for GA, with the differences between the groups becoming statistically significant five years after surgery (Fig. 2). After a maximum of 14 years of follow-up, patients who had been given NA were more likely to be alive (58.2\%; $95 \%$ confidence interval [CI] 50.4 to 66.0) compared with those who had been given GA $(57.3 \%$; $95 \%$ CI 51.4 to 63.2 , $P=0.009$ ).

During the study period, the NA group had significantly lower median (IQR) treatment costs, shorter median (IQR) LOS, and better long-term overall survival rates than the GA group. The costs were $\$ 4,079(3,806-4,444)$ vs $\$ 4,113$ (3,812-4,568), respectively $(P<0.001)$. LOS were 8 


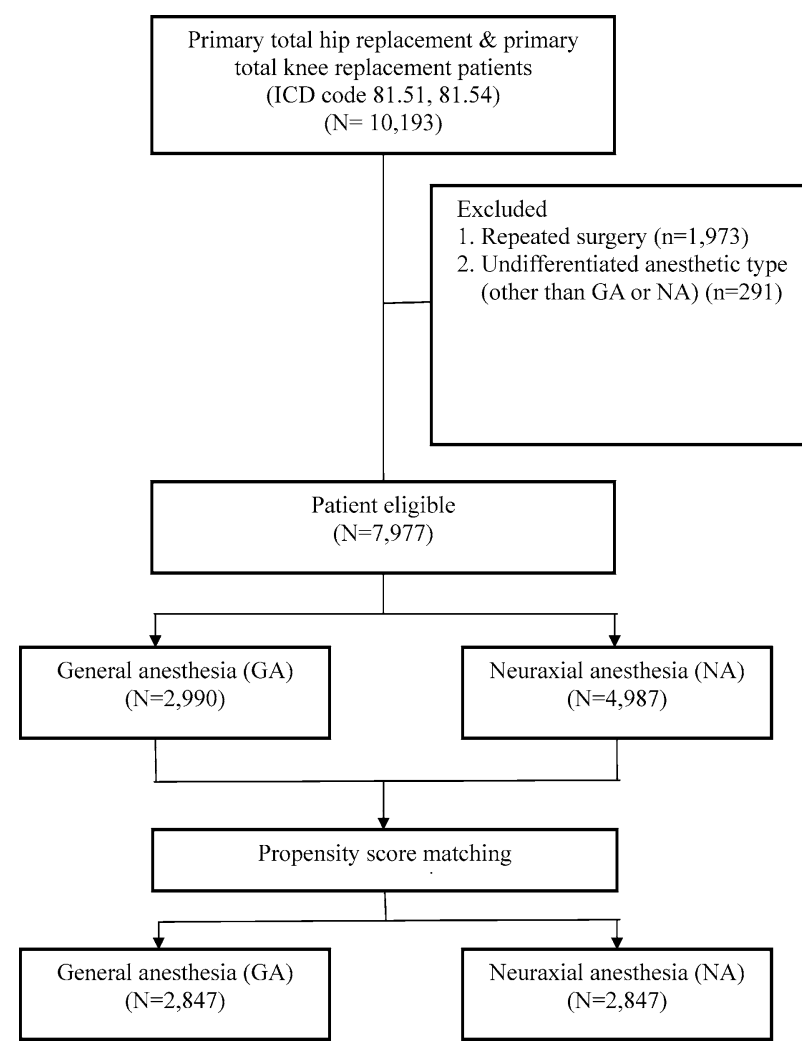

Fig. 1 Patient selection and study design

(7-10) days vs 8 (6-10) days, respectively $(P=0.024)$ (Table 2).

\section{Discussion}

This retrospective longitudinal study evaluated the effect of NA on the long-term survival rate in Asian patients undergoing TJR. Although the short-term survival rates were similar in the two groups, we found that patients in the NA group experienced shorter hospital stays, lower hospital costs, and improved long-term overall survival compared to those in the GA group.

In this longitudinal study in Taiwan, NA was given to $62.5 \%$ of patients undergoing TJR. In a US study by Memtsoudis et al., ${ }^{7}$ only $11.1 \%$ of nearly 400,000 patients undergoing TJR were given NA. This finding may imply that the preferred anesthetic technique chosen for patients undergoing TJR was different in Taiwan than in Western countries. This disparity may be attributed to cultural diversity, different reimbursement policies, preferences of physicians, or other, unidentified reasons.

Previous studies had identified a small 30-day mortality benefit of NA over GA after surgery. ${ }^{7,20}$ After studying a large nationwide sample in the United States, Memtsoudis et al. reported that the incidence of pulmonary complications (e.g., pulmonary embolism) is higher in patients undergoing GA than in those undergoing NA. ${ }^{7}$ Lee et $a l^{21}$ had reported that the incidence of pulmonary embolism was lower in Asian patients than in those from Western countries. Whether the difference in race leads to the conflicting short-term mortality results is unknown. The relatively small sample sizes in our study and the fewer short-term deaths after TJR also could cause some bias.

Our study of Asian patients undergoing TJR, with a follow-up of 14 years, revealed that NA may be responsible for improving the long-term survival rate compared with that after GA. This finding is consistent with the results reported by Monk et al., who found that the mortality rate during the first postoperative year might be affected by anesthetic management. ${ }^{22}$ In an observational study of 1,064 patients, they found that the Charlson comorbidity index score, cumulative deep hypnotic time, and intraoperative hypotension (systolic blood pressure $<80 \mathrm{mmHg}$ ) were significant independent predictors of the one-year mortality rate. Brown et al. also found that the hypnotic depth might be associated with the one-year mortality rate in elderly patients during repair of hip fractures under spinal anesthesia. ${ }^{23}$ We suggest that the long-term benefit of NA may be related to the more stable hemodynamic profile ${ }^{24}$ and the shallower hypnosis associated with NA than in those seen with GA. Another possible reason is that orthopedic surgery under NA is associated with less blood loss and blood transfusion requirement than are found with GA. ${ }^{4,5,25,26}$ Blood transfusion were identified as a predictor of long-term mortality following primary TJR in elderly individuals in a previous study. ${ }^{27}$ Although not statistically significant at the 0.05 level, it is apparent that there was a slightly lower co-morbidity index amongst patients in the NA group after propensity-score matching. This finding suggests a lower overall risk for the NA group, leading to improved outcomes later in life.

A meta-analysis evaluating the relative efficacy of regional anesthesia and GA in patients who had total hip or knee replacements did not find any discernible difference in the LOS between the groups (standardized mean difference: $-0.55 ; 95 \% \mathrm{CI},-2.47$ to 1.37 ; $P=0.120) .{ }^{4}$ In 2013, Pugely et al. studied the American College of Surgeons National Surgical Quality Improvement Program database and showed that patients who had undergone primary total knee replacement with spinal anesthesia had shorter LOS than those who had been given GA (3.45 vs 3.77 days). ${ }^{8}$ Memtsoundis et al. reported similar findings after studying data from a large US database. ${ }^{7}$ In our study, patients in the NA group had shorter LOS than those in the GA group, confirming that the findings noted in the North American health systems were similar to those from Asia. 
Table 1 Comparison between general anesthesia (GA) and neuraxial anesthesia (NA) before and after propensity score matching (PSM) ${ }^{\S}$

\begin{tabular}{|c|c|c|c|c|c|c|}
\hline \multirow[t]{2}{*}{ Characteristics } & \multicolumn{3}{|l|}{ Pre-PSM } & \multicolumn{3}{|l|}{ Post-PSM } \\
\hline & $\begin{array}{l}\text { GA }(n=2,990) \\
\%(n)\end{array}$ & $\begin{array}{l}\text { NA }(n=4,987) \\
\%(n)\end{array}$ & $P$ Value & $\begin{array}{l}\mathrm{GA}(n=2,847) \\
\%(\mathrm{~N})\end{array}$ & $\begin{array}{l}\text { NA }(n=2,847) \\
\%(\mathrm{~N})\end{array}$ & $P$ Value \\
\hline Age* & $62 \pm 13$ & $67 \pm 11$ & $<0.001$ & $64 \pm 12$ & $64 \pm 12$ & 0.830 \\
\hline Female & $63.9(1911)$ & $64.8(3232)$ & 0.201 & $64.7(1842)$ & $65.6(1868)$ & 0.244 \\
\hline $\mathrm{CCI}^{*}$ & $0.29 \pm 0.7$ & $0.25 \pm 0.6$ & 0.029 & $0.29 \pm 0.7$ & $0.27 \pm 0.6$ & 0.135 \\
\hline \multicolumn{7}{|l|}{ Comorbidity } \\
\hline Myocardial infarction & $<0.1(2)$ & $0.76(38)$ & $<0.001$ & $<0.1(2)$ & $<0.1(2)$ & 1.000 \\
\hline Congestive heart failure & $1.04(31)$ & $0.56(28)$ & 0.021 & $0.81(24)$ & $0.81(24)$ & 1.000 \\
\hline Cerebrovascular disease & $1.14(34)$ & $1.19(59)$ & 0.914 & $1.19(34)$ & $1.02(29)$ & 0.613 \\
\hline Dementia & $<0.1(1)$ & $0.14(7)$ & 0.272 & $<0.1(1)$ & $0.11(3)$ & 0.625 \\
\hline COPD & $1.54(46)$ & $2.37(118)$ & 0.011 & $1.55(44)$ & $1.90(54)$ & 0.311 \\
\hline Rheumatic disease & $2.32(69)$ & $1.85(92)$ & 0.162 & $2.11(60)$ & $2.25(64)$ & 0.785 \\
\hline Mild liver disease & $0.94(28)$ & $0.46(23)$ & 0.013 & $0.88(25)$ & $0.6(17)$ & 0.278 \\
\hline Severe liver disease & $1.17(35)$ & $0.86(43)$ & 0.196 & $1.23(35)$ & $0.84(24)$ & 0.190 \\
\hline Uncomplicated diabetes & $11.38(339)$ & $11.99(596)$ & 0.429 & $11.80(336)$ & $10.78(307)$ & 0.241 \\
\hline Complicated diabetes & $0.13(4)$ & $0.18(9)$ & 0.778 & $0.14(4)$ & $0.18(5)$ & 1.000 \\
\hline Renal disease & $0.81(24)$ & $0.82(41)$ & 1.000 & $0.77(22)$ & $0.81(23)$ & 1.000 \\
\hline Paraplegia & $<0.1(2)$ & $0.1(5)$ & 1.000 & $<0.1(2)$ & $0.14(4)$ & 0.687 \\
\hline Cancer & $0.70(21)$ & $0.4(20)$ & 0.076 & $0.42(12)$ & $0.39(11)$ & 0.839 \\
\hline AIDS & $<0.1(1)$ & $<0.1(1)$ & 1.000 & $<0.1(1)$ & $<0.1(1)$ & 1.000 \\
\hline \multicolumn{7}{|l|}{ Surgical type } \\
\hline TKR & $60.0(1794)$ & $77.5(3863)$ & $<0.001$ & $62.9(1790)$ & $64.9(1848)$ & 0.127 \\
\hline THR & $40.0(1196)$ & $22.5(1124)$ & & 37.1(1057) & 35.1(999) & \\
\hline High surgeon volume & $34.3(1026)$ & $41.9(2090)$ & $<0.001$ & $35.3(1005)$ & $34.8(991)$ & 0.349 \\
\hline High hospital volume & $41.0(1226)$ & $37.6(1875)$ & 0.001 & $39.8(1133)$ & 38.6(1099) & 0.180 \\
\hline
\end{tabular}

$\mathrm{CCI}=$ Charlson comorbidity index score; COPD = chronic obstructive pulmonary disease; AIDS = acquired immune deficiency syndrome; $\mathrm{TKR}=$ total knee replacement; THR = total hip replacement. ${ }^{\S}$ Cut-off value of high/low surgeon and hospital volume were calculated in each year through $1997 \sim 2010$. $*$ Values are means \pm standard deviation

Studies comparing the total hospital treatment costs of orthopedic surgery performed under NA and GA have been limited. After conducting a small randomized controlled trial to investigate the costs associated with GA and spinal anesthesia for elective hip or knee replacement, Gonano et al. found that spinal anesthesia is more cost-effective than GA as it is associated with lower fixed and variable costs. ${ }^{28} \mathrm{We}$ investigated the total hospital treatment costs for primary total hip or knee replacements performed in Taiwan from 1997 to 2010. As there was a significant difference in the costs of different anesthetic techniques we investigated the hospital treatment costs with and without anesthesia-related expenses. According to the reimbursement policy of the BNHI, the average cost of GA is two to three times higher than that of NA for the same surgical procedure. The results reported in Table 2 indicate that the NA group clearly had significantly lower hospital costs than the GA group, even when the anesthesia cost was omitted. For example, the NA group had significantly lower pharmacy costs during hospitalization after TJR. The likely explanation is that the
NA group had less postoperative nausea/vomiting ${ }^{4}$ and better postoperative pain relief. ${ }^{29}$ Memtsoundis et al. concluded that $3 \%$ of patients undergoing TJR required critical care service (CCS), and CCS patients had higher mortality rates, longer hospital stays, and higher hospital costs. ${ }^{30}$ Risk factors for CCS are GA, advanced age, and postoperative cardiopulmonary complications. We were not able to identify a relation between anesthetic techniques and CCS because of limitations in the administrative data used.

Previous observational studies have obtained similar results regardless of whether confounders were adjusted by conventional logistic regression or by propensity-score matching. ${ }^{31,32}$ We used propensity-score matching to reduce the confounding factors between the two anesthetic methods by matching the patients' age, sex, comorbidities, surgery type, and hospital and surgeon volumes. High surgeon or hospital volume is associated with better outcomes in terms of medical utilization and complications/mortality for TJR procedures. $^{14-16}$ High surgical volumes increase the opportunity to improve surgical skills and implement a 


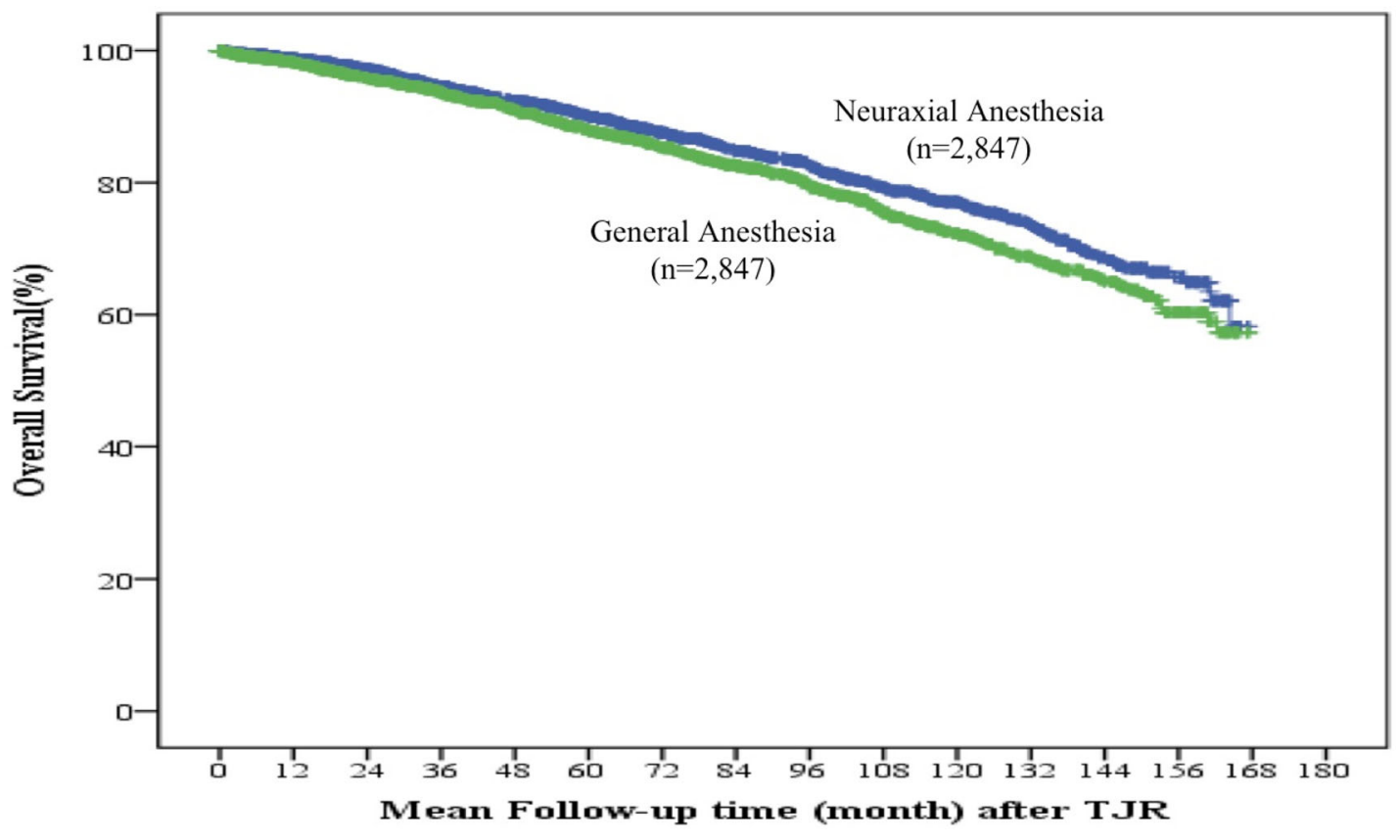

\begin{tabular}{lccccc}
\hline \multicolumn{4}{c}{ Mean follow-up time (Months) } & \multicolumn{4}{c}{ Survival rate (95\% C.I.) } \\
\hline Group & Mean $\pm \mathrm{SD}$ & $1^{\text {st }}$ Year $(\%)$ & $3^{\text {rd }}$ Year $(\%)$ & $5^{\text {th }}$ Year (\%) & Overall (\%) \\
\hline General anesthesia & $135.8 \pm 1.3$ & $98.1(97.5-98.7)$ & $93.6(92.6-94.6)$ & $87.8(86.4-89.2)$ & $57.3(51.4-63.2)$ \\
Neuraxial anesthesia & $140.2 \pm 1.2$ & $98.8(98.4-99.3)$ & $94.6(93.6-95.6)$ & $90.0(88.6-91.4)$ & $58.2(50.4-66.0)$ \\
\hline Log rank test ( P value) & & 0.071 & 0.054 & 0.023 & 0.009 \\
\hline TJR= total joint replacement: SD $=$ standard deviation $95 \%$ C. $=95 \%$ confidence interval.
\end{tabular}

Fig. 2 Five-year overall survival rate after TJR between GA and NA. TJR = total joint replacement; GA = general anesthesia; NA = neuraxial anesthesia

Table 2 Medical utilization and long-term outcomes between general anesthesia (GA) and neuraxial anesthesia (NA) after propensity score matching (PSM) \#

\begin{tabular}{|c|c|c|c|}
\hline Characteristics & GA & NA & $P$ Value $^{\S}$ \\
\hline Patient number & 2,847 & 2,847 & \\
\hline Length of stay, days* & $8(6-10)$ & $8(7-10)$ & 0.024 \\
\hline Hospital charges, dollars* & $4,423(4,108-4,892)$ & $4,202(3,916-4,579)$ & $<0.001$ \\
\hline Hospital charges, dollars (without anesthetic cost)* & $4,113(3,812-4,569)$ & $4,079(3,806-4,444)$ & $<0.001$ \\
\hline Special material* & $2,309(2,186-2,552)$ & $2,350(2,214-2,528)$ & 0.140 \\
\hline Surgeon $(\mathrm{s})^{*}$ & $962(962-993)$ & $962(962-993)$ & 0.220 \\
\hline Anesthesia* & $310(296-324)$ & $123(110-135)$ & $<0.001$ \\
\hline Hospital room* & $298(233-353)$ & $250(206-316)$ & $<0.001$ \\
\hline Pharmacy* & 121(69-166) & $96(61-135)$ & $<0.001$ \\
\hline Radiology* & $100(88-120)$ & $97(83-105)$ & $<0.001$ \\
\hline Laboratory* & $110(83-140)$ & $101(75-121)$ & $<0.001$ \\
\hline Physical therapy* & $32(20-55)$ & $21(15-32)$ & $<0.001$ \\
\hline Others (hemodialysis, meals et al.)* & 182(171-188) & $204(189-213)$ & $<0.001$ \\
\hline Overall survival after TJR (\%) & 57 & 58 & 0.009 \\
\hline
\end{tabular}

${ }^{\#}$ Shapiro-Wilk test was used to assess for the normal distribution $(P<0.05)$. Values are medians (interquartile range); ${ }^{\S} \mathrm{Wilcoxon}$ sum rank test was used. TJR $=$ total joint replacement 
cost-effective model for treatment. After adjusting for hospital and surgeon volumes, our results became more reliable.

Our study had certain limitations that are inherent to studies analyzing large databases. First, the clinical perspective obtained from the claims data is likely not as accurate as that obtained from prospective clinical trial data because claims data can include errors in the coding of primary diagnoses and surgical modalities. Second, information was not available regarding the American Society of Anesthesiologists class, body mass index, preoperative laboratory values, intraoperative parameters, postoperative pain management, or other confounding factors that could potentially influence postoperative outcomes and long-term survival. Third, complications associated with anesthesia or surgery were not assessed, which may limit the validity of our predictions. Finally, we did not examine outcome data, such as patient-reported quality of life and indirect costs incurred after discharge.

\section{Conclusions}

Our study results showed that the long-term survival of patients who underwent primary total knee or hip replacements was better for patients given NA than for those given GA. The NA group also experienced shorter LOS and lower hospital treatment costs than the GA group. The association of NA with improved long-term survival remains unexplained. Further studies are needed to both confirm the association of longer survival with NA and identify its mechanism.

Financial disclosure None to disclose.

Conflict of interest None declared.

\section{References}

1. Kurtz S, Ong K, Lau E, Mowat F, Halpern M. Projections of primary and revision hip and knee arthroplasty in the United States from 2005 to 2030. J Bone Joint Surg Am 2007; 89: 780-5.

2. Modig J, Borg T, Karlstrom G, Maripuu E, Sahlstedt B. Thromboembolism after total hip replacement: role of epidural and general anesthesia. Anesth Analg 1983; 62: 174-80.

3. Modig J, Borg T, Bagge L, Saldeen T. Role of extradural and of general anaesthesia in fibrinolysis and coagulation after total hip replacement. Br J Anaesth 1983; 55: 625-9.

4. Hu S, Zhang ZY, Hua YQ, Li J, Cai ZD. A comparison of regional and general anaesthesia for total replacement of the hip or knee: a meta-analysis. J Bone Joint Surg Br 2009; 91: 935-42.

5. Mauermann WJ, Shilling AM, Zuo Z. A comparison of neuraxial block versus general anesthesia for elective total hip replacement: a meta-analysis. Anesth Analg 2006; 103: 1018-25.

6. Macfarlane AJ, Prasad GA, Chan VWS, Brull R. Does regional anesthesia improve outcome after total knee arthroplasty? Clin Orthop Relat Res 2009; 467: 2379-402.
7. Memtsoudis SG, Sun X, Chiu YL, et al. Perioperative comparative effectiveness of anesthetic technique in orthopedic patients. Anesthesiology 2013; 118: 1046-58.

8. Pugely AJ, Martin CT, Gao Y, Mendoza-Latters S, Callahan JJ. Differences in short-term complications between spinal and general anesthesia for primary total knee arthroplasty. J Bone Joint Surg Am 2013; 95: 193-9.

9. Biki B, Mascha E, Moriarty DC, Fitzpatrick JM, Sessler DI, Buggy DJ. Anesthetic technique for radical prostatectomy surgery affects cancer recurrence: a retrospective analysis. Anesthesiology 2008; 109: 180-7.

10. de Oliveira GS Jr, Ahmad S, Schink JC, Singh DK, Fitzgerald $P C, M c$ Carthy RJ. Intraoperative neuraxial anesthesia but not postoperative neuraxial analgesia is associated with increased relapse-free survival in ovarian cancer patients after primary cytoreductive surgery. Reg Anesth Pain Med 2011; 36: 271-7.

11. Parker MJ, Handoll HH, Griffiths R. Anaesthesia for hip fracture surgery in adults. Cochrane Database Syst Rev 2004; 4: CD000521.

12. White SM, Moppett IK, Griffiths R. Outcome by mode of anaesthesia for hip fracture surgery. An observational audit of 65 535 patients in a national dataset. Anaesthesia 2014; 69: 224-30.

13. Santaguida PL, Hawker GA, Hudak PL, et al. Patient characteristics affecting the prognosis of total hip and knee joint arthroplasty: a systematic review. Can J Surg 2008; 51: 428-36.

14. Hervey SL, Purves HR, Guller U, Toth AP, Vail TP, Pietrobon R. Provider volume of total knee arthroplasties and patient outcomes in the HCUP-nationwide inpatient sample. J Bone Joint Surg Am 2003; 85-A: 1775-83.

15. Katz JN, Barrett J, Mahomed NN, Baron JA, Wright RJ, Losina $E$. Association between hospital and surgeon procedure volume and the outcomes of total knee replacement. J Bone Joint Surg Am 2004; 86-A: 1909-16.

16. Shi HY, Chang JK, Chiu HC. Volume associations in total hip arthroplasty: a nationwide Taiwan population-based study. J Arthroplasty 2013; 28: 1834-8.

17. Rubin $D B$. Estimating causal effects from large data sets using propensity scores. Ann Intern Med 1997; 127(8 Pt 2): 757-63.

18. Rubin $D B$. The design versus the analysis of observational studies for causal effects: parallels with the design of randomized trials. Stat Med 2007; 26: 20-36.

19. Austin PC. Propensity-score matching in the cardiovascular surgery literature from 2004 to 2006: a systematic review and suggestions for improvement. J Thorac Cardiovasc Surg 2007; 134: 1128-35.

20. Wijeysundera DN, Beattie WS, Austin PC, Hux JE, Laupacis A. Epidural anaesthesia and survival after intermediate-to-high risk non-cardiac surgery: a population-based cohort study. Lancet 2008; 372: 562-9.

21. Lee WS, Kim KI, Lee HJ, Kyung HS, Seo SS. The incidence of pulmonary embolism and deep vein thrombosis after knee arthroplasty in Asians remains low: a meta-analysis. Clin Orthop Relat Res 2013; 471: 1523-32.

22. Monk TG, Saini V, Weldon BC, Sigl JC. Anesthetic management and one-year mortality after noncardiac surgery. Anesth Analg 2005; 100: 4-10.

23. Brown CH 4th, Azman AS, Gottschalk A, Mears SC, Sieber FE. Sedation depth during spinal anesthesia and survival in elderly patients undergoing hip fracture repair. Anesth Analg 2014; 118: 977-80.

24. Messina A, Frassanito L, Colombo D, et al. Hemodynamic changes associated with spinal and general anesthesia for hip fracture surgery in severe ASA III elderly population: a pilot trial. Minerva Anestesiol 2013; 79: 1021-9.

25. Macfarlane AJR, Prasad GA, Chan VW, Brull R. Does regional anaesthesia improve outcome after total hip arthroplasty? A systematic review. Br J Anaesth 2009; 103: 335-45. 
26. Guay J. The effect of neuraxial blocks on surgical blood loss and blood transfusion requirements: a meta-analysis. J Clin Anesth 2006; 18: 124-8.

27. Jamsen E, Puolakka T, Eskelinen A, et al. Predictors of mortality following primary hip and knee replacement in the aged. A single-center analysis of 1,998 primary hip and knee replacements for primary osteoarthritis. Acta Orthop 2013; 84: 44-53.

28. Gonano C, Leitgeb U, Sitzwohl C, Ihra G, Weinstabl C, Kettner $S C$. Spinal versus general anesthesia for orthopedic surgery: anesthesia drug and supply costs. Anesth Analg 2006; 102: 524-9.

29. Chu CP, Yap JC, Chen PP, Hung HH. Postoperative outcome in Chinese patients having primary total knee arthroplasty under general anaesthesia/intravenous patient-controlled analgesia compared to spinal-epidural anaesthesia/analgesia. Hong Kong Med J 2006; 12: 442-7.

30. Memtsoudis SG, Sun X, Chiu YL, et al. Utilization of critical care services among patients undergoing total hip and knee arthroplasty: epidemiology and risk factors. Anesthesiology 2012; 117: 107-16.

31. Cepeda MS, Boston R, Farrar JT, Strom BL. Comparison of logistic regression versus propensity score when the number of events is low and there are multiple confounders. Am J Epidemiol 2003; 158: 280-7.

32. Shah BR, Laupacis A, Hux JE, Austin PC. Propensity score methods gave similar results to traditional regression modeling in observational studies: a systematic review. J Clin Epidemiol 2005; 58: 550-9. 